\title{
KEWIRAUSAHAAN SOSIAL SEBAGAI LANDASAN TRANSFER TEKNOLOGI (STUDI KASUS TAMBAK UDANG SUMBAWA)
}

\author{
Indra Kurniawan', Arif Budi Witarto' ${ }^{2}$, Zulkiflienmansyah ${ }^{3}$ \\ ${ }^{1}$ Magister Manajemen Inovasi, Universitas Teknologi Sumbawa. \\ E-mail: samawaindra@yahoo.co.id \\ ${ }^{2}$ Magister Manajemen Inovasi, Universitas Teknologi Sumbawa. \\ ${ }_{3}^{3}$ Magister Manajemen Inovasi, Universitas Teknologi Sumbawa.
}

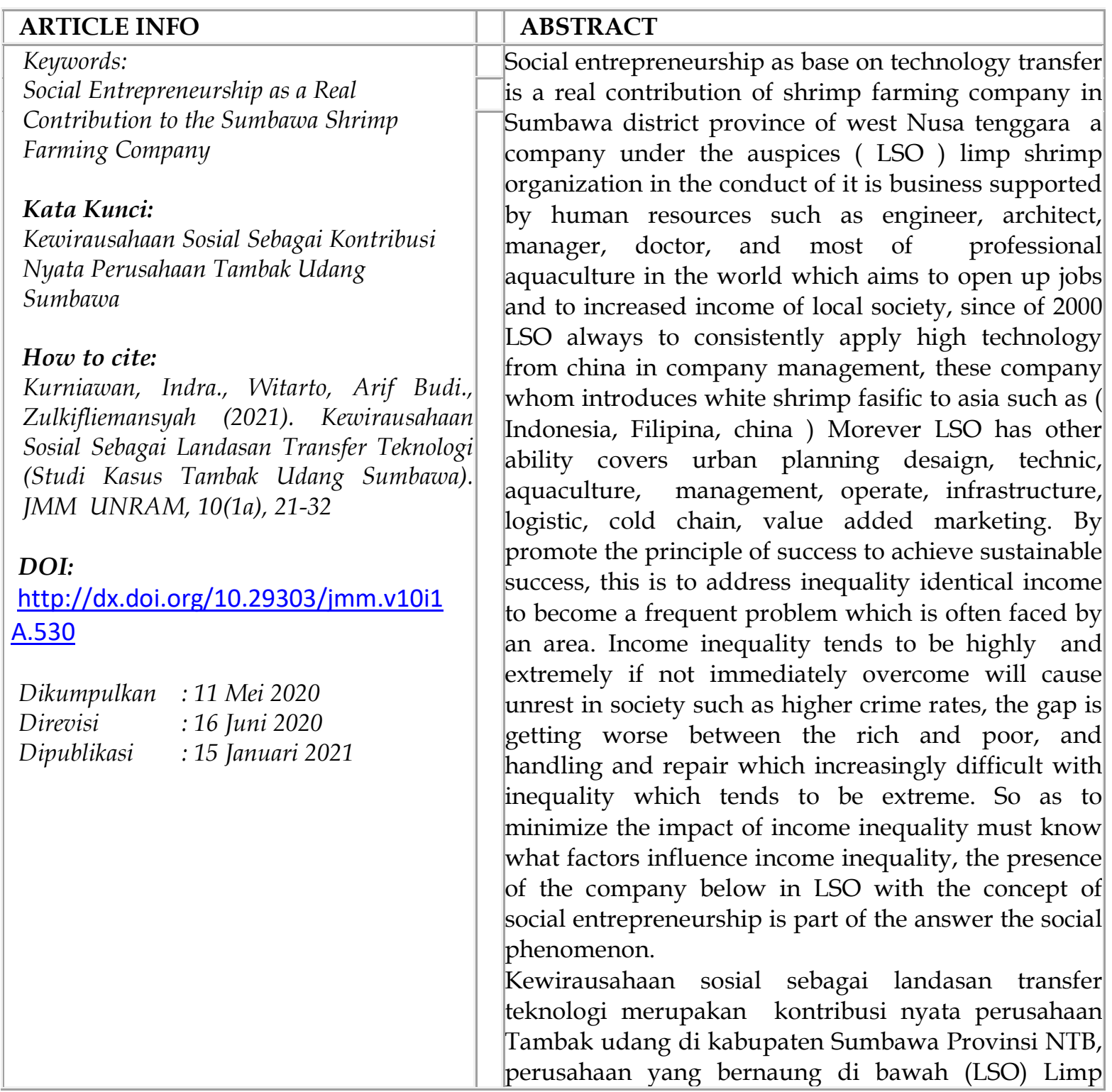




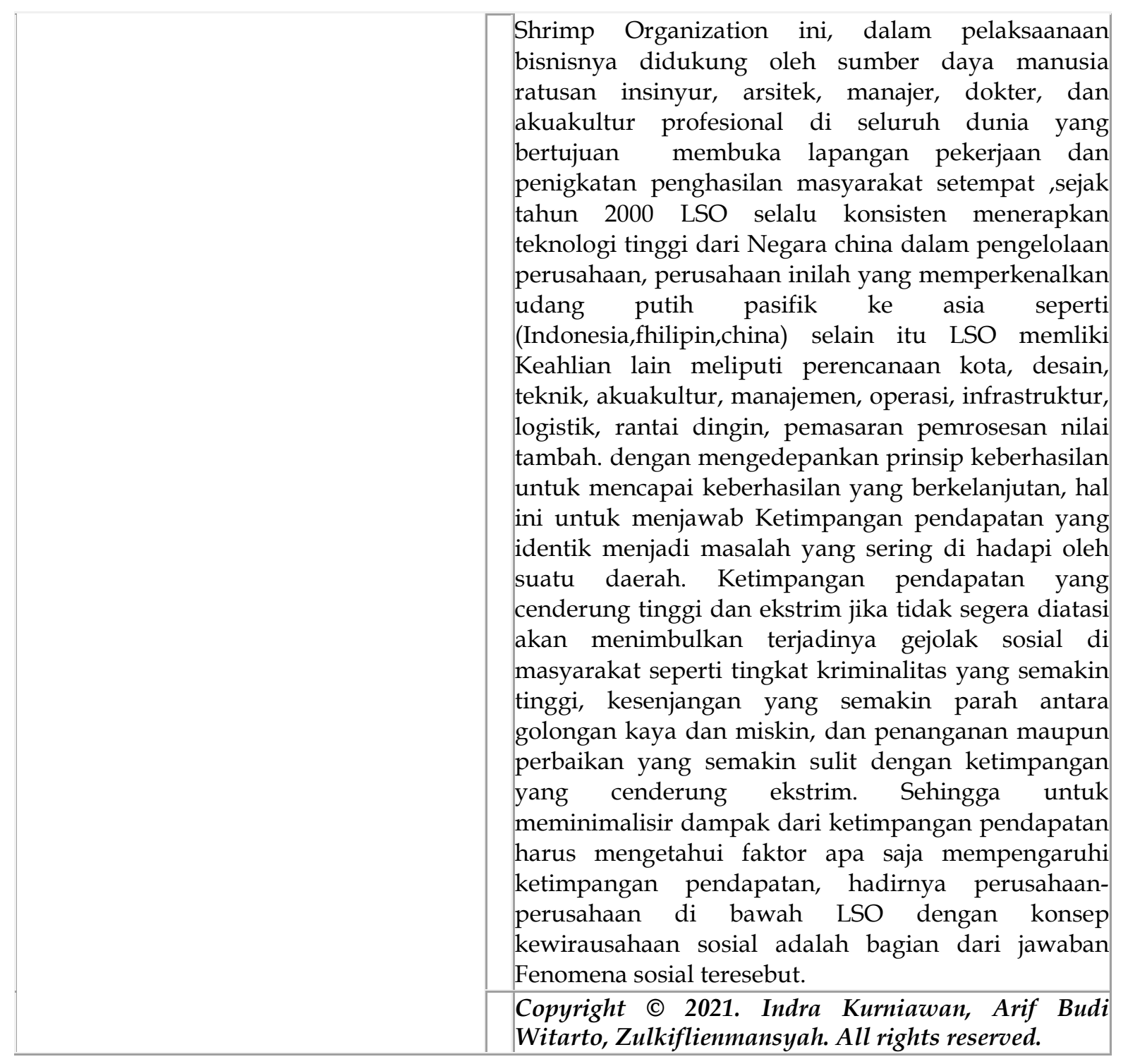

\section{PENDAHULUAN}

Kabupaten Sumbawa sebagai salah satu daerah dari sepuluh kabupaten/kota yang berada di wilayah Propinsi Nusa Tenggara Barat terletak di ujung barat Pulau Sumbawa, pada posisi 116" 42' sampai dengan 118" 22' Bujur Timur dan 8" 8' sampai dengan 9" 7' Lintang Selatan serta memiliki luas wilayah 6.643,98 Km2. Dengan potensi perairan yang bagus dan luas kabupaten Sumbawa tentu akan menjadi tujuan investasi di sektor perikanan terutama tambak udang salah satunya operator perusahaan multi nasional yang tertarik berinvestasi di kabupaten Sumbawa adalah LIM SHRIMP ORGANIZATION.adalah perusahaan yang terdaftar di Singapura,yang telah memiliki rekam jejak 30 tahun lebih menagani projek baik swasta dan pemerintah di berbagai Negara, sebagai operator terbesar di berbagi Negara di dunia seperti papua, timor laste, Vietnam, oman, Malaysia, china, laos, thailand, Puerto riko, spanyol, afrika dan rusia. Sektor perikanan budidaya udang juga merupakan komuditas unggulan, hal ini di dasarkan karena perencanaan berbasis special, pengembagan berbasis kawasan strategis daerah, serta merupakan potensi komparatif daerah karna memiliki peluang penyerapan 
tenaga kerja yang cukup besar, peluang keterbukaan pasar yang luas, dari sisi lingkungan budidaya udang sangat ramah lingkungan dan yang terpenting memiliki jaminan keberlanjutan usaha dan memiliki peluang alih teknologi karena dapat di kuasai oleh masyarakat,dalam pelaksaanaan bisnisnya LSO selalu megedapankan konsep kewirausahaan sosial yang bertujuan membuka lapangan pekerjaan dan penigkatan penghasilan masyarakat setempat.

\section{METODE PENELITIAN}

Penelitian merupakan alat atau sarana utama dalam mengembangkan ilmu pengetahuan dan teknologi yang bertujuan untuk mengungkap kebenaran secara sistematika, metodologis dan konsisten. Melalui proses penelitian tersebut, maka sangat perlu diadakan analisis dan konstruksi terhadap data yang telah dikumpulkan dan diolah.(soerjono soekanto \& mamudji,2001)

\subsection{Jenis Penelitian}

Penelitian ini menggunakan jenis penelitian kualitatif deskriptif. Penelitian kualitatif adalah penelitian untuk memahami fenomena tentang apa yang dialami oleh subjek penelitian misalnya perilaku, persepsi, motivasi, tindakan, secara holistik, dan dengan cara deskripsi dalam bentuk kata-kata dan bahasa, pada suatu konteks khusus yang alamiah dan dengan memanfaatkan berbagai metoda ilmiah (Moleong, 2014). Data yang dikumpulkan dalam pelitian kualitatif deskriptif berupa kata-kata atau gambar sehingga informasi yang didapatkan akan lebih lengkap, lebih mendalam, kredibel, dan bermakna sehingga tujuan penelitian dapat dicapai.

\subsection{Sumber Data}

Sumber Data yang digunakan dalam penelitian ini meliputi:

1) Data Primer

Data primer yaitu data yang diperoleh langsung di lapangan dari responden melalui wawancara. Wawancara adalah percakapan dengan tujuan tertentu yang dilakukan oleh dua pihak, yaitu pewawancara (interviewer) yang mengajukan pertanyaan dan terwawancara (interviewee) yang memberikan jawaban atas pertanyaan itu (Moleong, 2014).

2) Data Sekunder

Data sekunder yaitu pengumpulan data melalui studi dokumentasi. Studi dokumentasi adalah salah satu metoda pengumpulan data kualitatif dengan melihat atau menganalisis dokumen-dokumen yang dibuat oleh subjek sendiri atau oleh orang lain tentang subjek (Herdiansyah, 2010).

3) Studi Kepustakaan

Studi kepustakaan dilakukan dengan cara mengadopsi teori-teori umum dari berbagai literatur, tesis, jurnal, buku-buku dengan topik yang relevan dan sesuai keperluan penelitian serta artikel-artikel dari website dalam rangka mendapatkan landasan teori yang mendukung penelitian.

\section{4) Teknik Pengumpulan Data}

Teknik pengumpulan data yang digunakan yakni wawancara dan dokumentasi. Penjelasan mengenai hal tersebut antara lain: 
1) Wawancara

Esterberg (2002) menjelaskan wawancara merupakan pertemuan antara dua orang yang saling bertukar informasi dan ide melalui tanya jawab, sehingga dapat dibangun makna dalam suatu topik tertentu (dalam Sugiyono, 2014). Wawancara yang digunakan dalam penelitian ini merupakan wawancara semi terstruktur yaitu teknik wawancara yang lebih bebas dimana pihak yang diwawancara dimintai pendapat dan ide-ide dengan tujuan untuk menemukan permasalahan secara lebih terbuka.

2) Dokumentasi dan analisis data

Dokumentasi dilakukan dengan cara mengumpulkan dan mempelajari dokumendokumen dan informasi yang terkait dengan penelitian.

Analisis Data Menurut Miles and Huberman (1984) dalam Sugiyono (2014), teknik analisis terdiri dari tiga tahap yaitu reduksi data, penyajian data, dan tahap penarikan kesimpulan. 1) Reduksi Data Mereduksi data menurut Sugiyono (2014) berarti merangkum, memilih hal-hal yang pokok, memfokuskan pada hal-hal yang penting, dicari tema dan polanya. Dengan demikian data yang telah direduksi akan memberikan gambaran yang lebih jelas, dan mempermudah peneliti untuk melakukan pengumpulan data selanjutnya, dan mencarinya bila diperlukan.Penyajian Data Setelah proses reduksi data selesai langkah selanjutnya adalah penyajian data.

1. Penyajian Data

Setelah proses reduksi data selesai langkah selanjutnya adalah penyajian data. Pada tahapan ini data hasil reduksi disajikan dalam bentuk uraian singkat, bagan, hubungan antar kategori, flowchart, dan sejenisnya. Dengan menyajikan data, maka akan memudahkan untuk memahami apa yang terjadi, merencanakan kerja selanjutnya berdasarkan apa yang telah dipahami tersebut.

2. Penarikan Kesimpulan

Setelah data disajikan, langkah selanjutnya adalah penarikan kesimpulan dan verifikasi. Kesimpulan awal yang dikemukakan masih bersifat sementara, dan akan berubah apabila tidak ditemukan bukti-bukti yang kuat yang mendukung pada tahap pengumpulan data berikutnya. Namun apabila kesimpulan awal tersebut didukung oleh bukti-bukti yang valid dan konsisten, maka kesimpulan tersebut merupakan kesimpulan yang kredibel (Sugiyono, 2014).

\section{PEMBAHASAN}

3.1. Bagaimana model pengembangan investasi budidaya tambak dan peningkatan kesejahteraan masyatakat lokal di kab.Sumbawa

Saat ini usaha budidaya udang sudah mulai menggeliat di Sumbawa, Produksi perikanan di Kabupaten Sumbawa pada tahun 2015 mencapai 736.127 .25 ton, yang berasal dari usaha penangkapan 52.234,29 ton, dan budidaya perikanan 683.892,96 ton

Dengan telah di keluarkan tiga dasar hukum dalam menopang kebijakan umum pembangunan perikanan budidaya udang di kabupaten Sumbawa telah membentuk wilayah kawasan yang dapat di lihat dari pembagian KSK dalam bentuk RTRW kabupaten Sumbawa dalam gambar sebagai berikut: 
Gambar 1.1

pembagian KSK dalam bentuk RTRW kabupaten Sumbawa

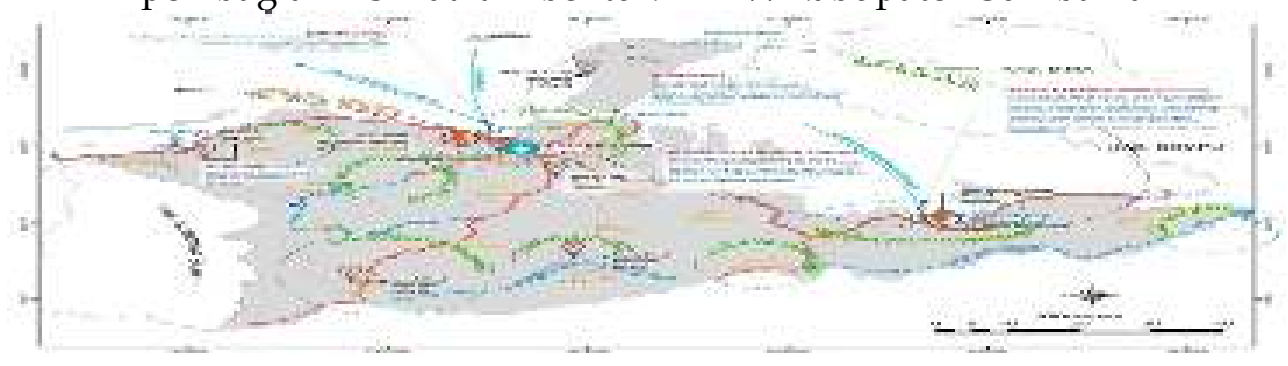

Data diolah dari Bapeda kabupaten Sumbawa

Gambar 1.2 wilayah pengembangan perikanan budidaya kabupaten Sumbawa

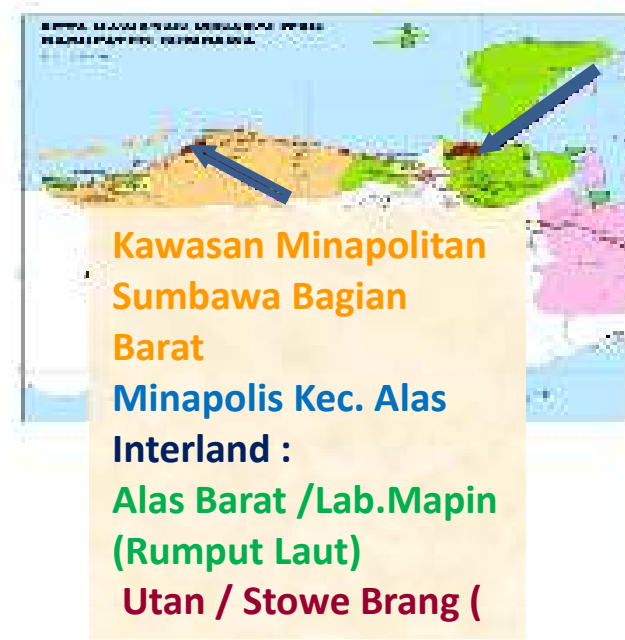

Kawasan Minapolitan Sumbawa Bagian Tengah

Minapolis Kec. Labuhan Badas Interind :

Moyohilir/ Tanjung bele (Rumput Laut) Moyo Utara/Penyaring ( Udang), Labuhan Badas/ PI. Laut, Lab.bontong : Udang)

Plampang (Spayung, Teluk Santong : Udang),

Maronge (Lab. Sangoro: Rumput Laut, Udang) Lape (Lab.Kuris :

Rumput Laut dan

Data diolah dari Bapeda kabupaten Sumbawa

Gambar 1.3 peta kawasan minapolitan komoditi udang kabupaten Sumbawa

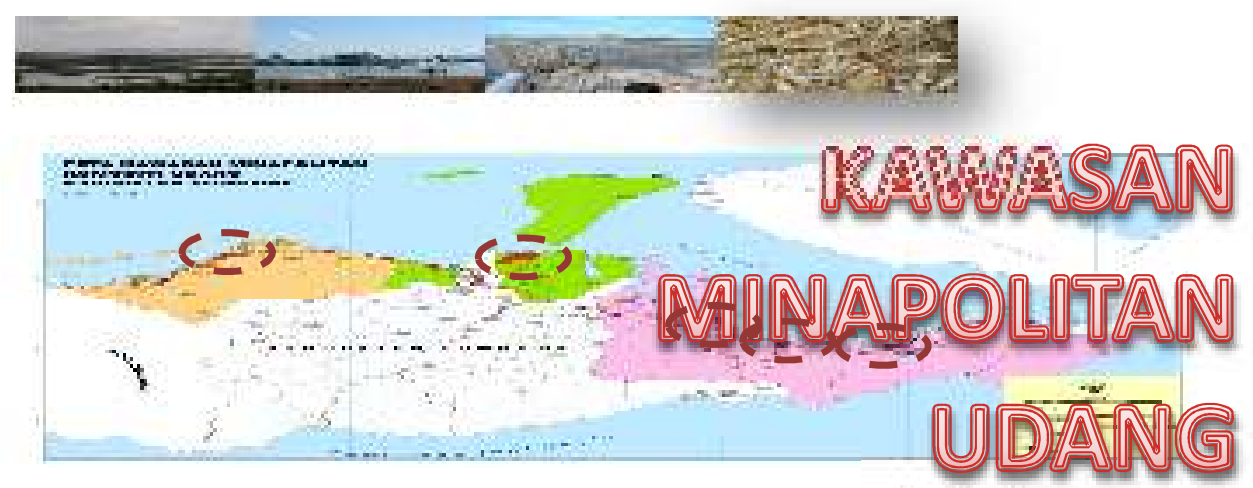

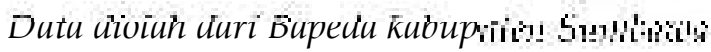


Gambar 1.4 produksi perikanan budidaya udang kabupaten Sumbawa dalam 5 tahun terkhir

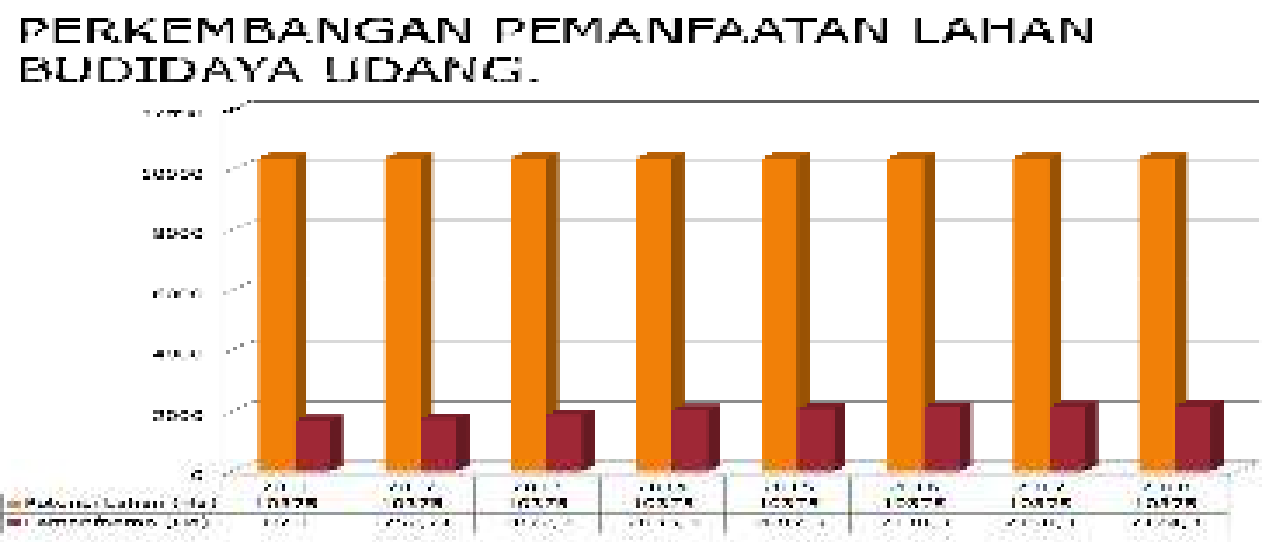

FOTEMMSI DAM IREALISAANI

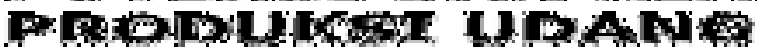

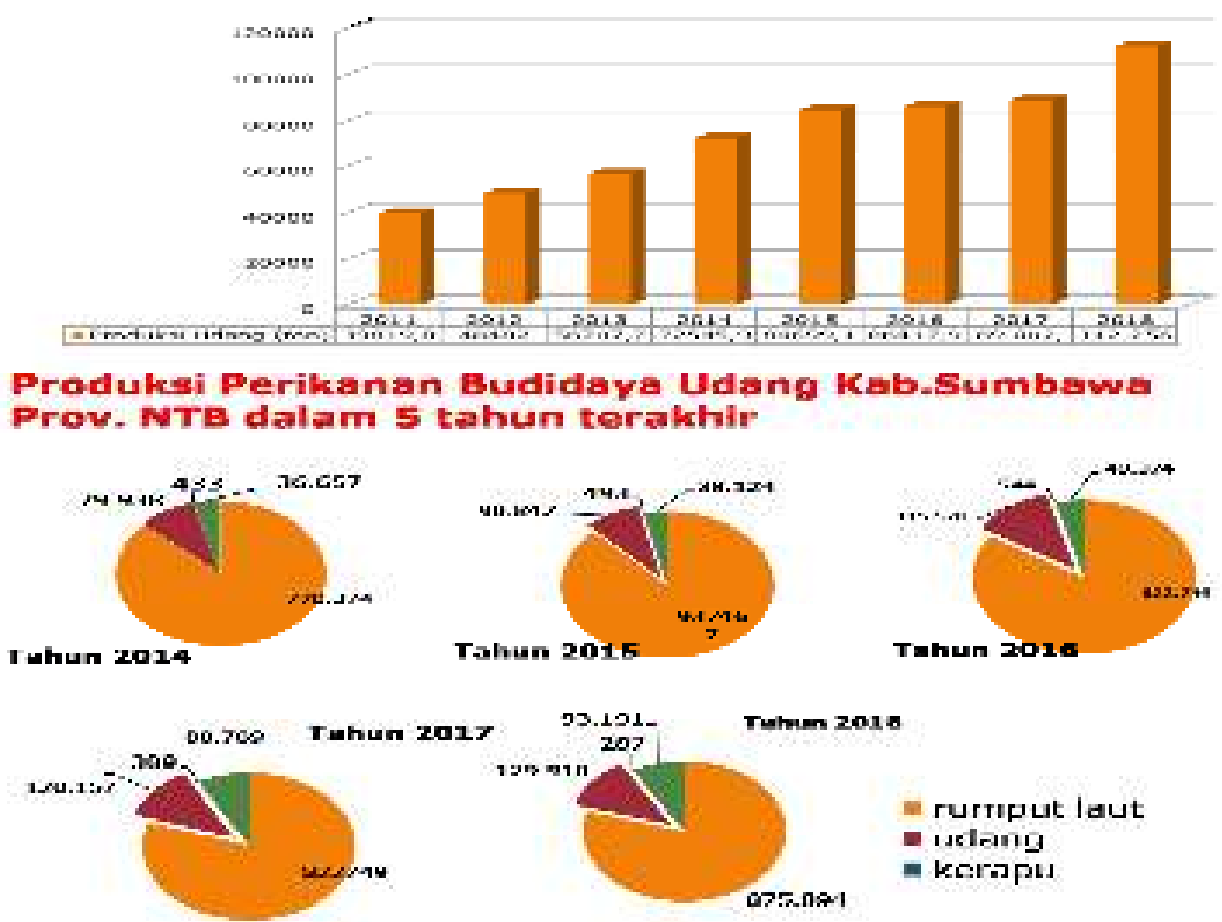

Data diolah dari Bapeda kabupaten Sumbawa 
Gambar 1.5

grafik produksi budidaya udang vaname,windu di

kabupaten Sumbawa dalam 5 tahun terakhir

\section{Produksi udang (Vaname, Windu dll) di}

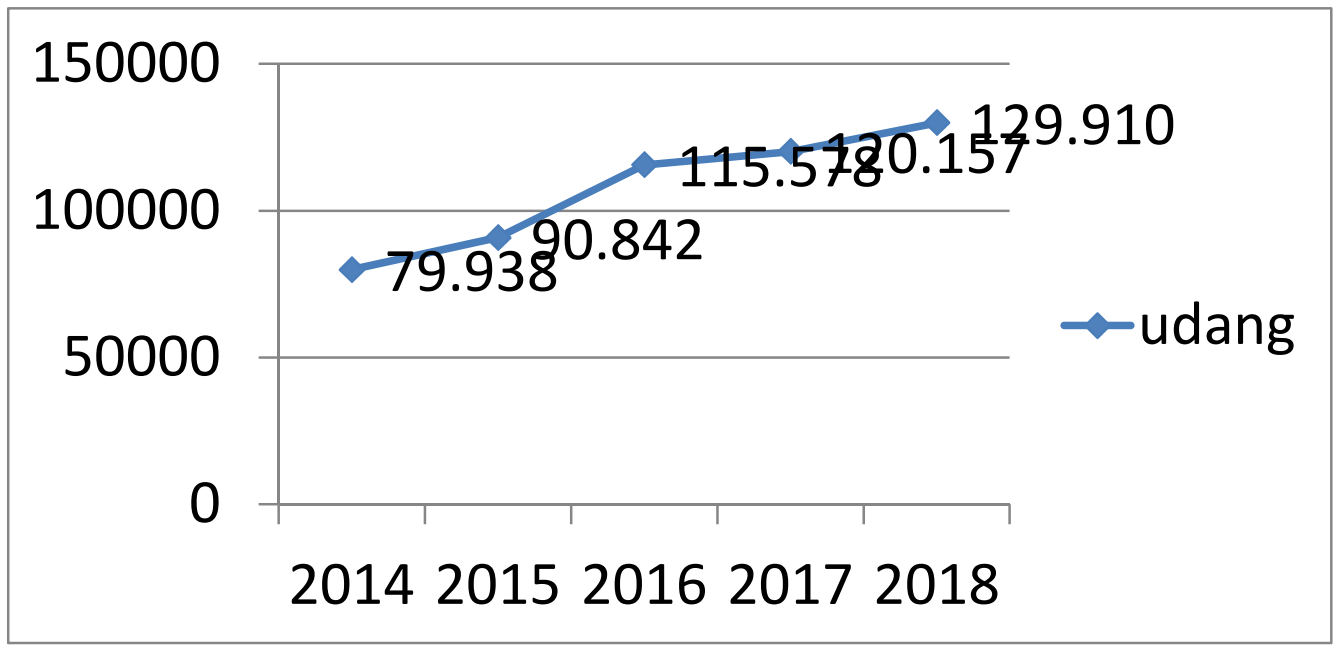

Data diolah dari Bapeda kabupaten Sumbawa

atas dasar Rancanagan tata letak wilayah perikanan Kab.Sumbawa dalam mengembangkan bisnisnya dalam dua tahun ini LSO melaui PT.LIMS SHRIM BERKAT BERSAMA sudah menginvestasikan modal kurang lebih 250 milyar dengan jumlah lahan yang sudah di HGU kan $200 \mathrm{Ha}$, untuk mewudkan visinya mengurangi dalam rangka penciptaan lapangan pekerjaan dan meningkatkan moralitas maka di buatlah konsep pengembangan bisnis budiya udang di LSO adalah Aqua village yang rata-rata farmnya di bawah $10 \mathrm{Ha}$,konsep ini di lakukan agar lokasi investasi dapat menyebar di kabupaten Sumbawa.(wawancara Mr.Ronal),

Adapun perusahaan yang bernaung di bawah LSO dalam perikrutan tenaga kerja selalu megutamakan tenaga kerja lokal setempat berikut daftar perusahaan dan jumlah karyawan yang bekerja,dapat di lihat di tabel :

Tabel 1.1

Daftar nama-nama perusahaan yang di operatori oleh LSO

\begin{tabular}{|l|l|c|c|c|}
\hline \multicolumn{1}{|c|}{ Nama peusahaan } & \multicolumn{1}{|c|}{ Alamat } & $\begin{array}{c}\text { Jumalah } \\
\text { karyawan }\end{array}$ & \multicolumn{2}{c|}{$\begin{array}{c}\text { Jenis } \\
\text { kelamain }\end{array}$} \\
\cline { 2 - 4 } & & L & P \\
\hline PT.morgan jaya sakti & Jl.garuda no.79 lempeh NTB & 7 & 4 \\
\hline $\begin{array}{l}\text { PT.Sumenelis berkat } \\
\text { bersama }\end{array}$ & $\begin{array}{l}\text { Ds,penyengar desa stowe berang } \\
\text { kecamatan utan }\end{array}$ & 15 & 13 & 2 \\
\hline PT.Bukit sedap aquakultur & Ds,omo desa penyaring kec,moyo utara & 10 & 10 & 0 \\
\hline PT.samawa tiga berkat & Ds rapang desa motong kecamatan utan & 19 & 18 & 1 \\
\hline
\end{tabular}




\begin{tabular}{|l|l|c|c|c|}
\hline $\begin{array}{l}\text { PT.tanjung samawa } \\
\text { vanamai }\end{array}$ & Ds rapang desa motong kecamatan utan & 14 & 14 & 0 \\
\hline PT.cidera jaya lestari & Ds rapang desa motong kecamatan utan & 23 & 23 & 0 \\
\hline $\begin{array}{l}\text { PT.sumbawa delapan } \\
\text { penjuru }\end{array}$ & $\begin{array}{l}\text { Ds .semagat baru desa gontar baru } \\
\text { kecamatanlas barat Sumbawa }\end{array}$ & 15 & 15 & 0 \\
\hline
\end{tabular}

\section{Data diolah dari LSO}

dari data jumlah tenaga kerja kerja lokal yang di pekerjaan oleh perusahaan maka terjadi peningkatan pendapatan perkapita masyarakat setempat dalam satu bulan jika dikalikan dengan Upah minimum kabupaten Sumbawa tahun 2020 maka total perputaran uang perbualan sebagai berikut:

\begin{tabular}{|c|c|c|}
\hline Jumlah tenga kerja & Umk kab.sumbawa tahun & jumlah \\
\hline 103 pekerja & Rp.2020 201.913 & Rp.226.797.039 \\
\hline & & \\
\hline
\end{tabular}

di samping merekrut tenga kerja tetap,perusahaan juga merekru tenaga kerja harian lepas di waktu penen yang merupakan ibu-ibu setempat dengan sistim penggajian upah harian, jika setiap Aqua village rata-rata panen dalam setahun sebanyak tiga kali dengan jumlah pekerja harian lepas samapi dengan 50 orang pekerja maka jumlah peningkatan penghasilan dapat di lihat sebagai berikut :

\begin{tabular}{|c|c|c|}
\hline $\begin{array}{c}\text { Jumlah tenaga kerja harian } \\
\text { lepas/panen }\end{array}$ & Upah harian & jumlah \\
\hline 50 pekerja & Rp.80.000 & Rp.4.000.000 \\
\hline
\end{tabular}

dari jumlah upah pekerja tetap dan uoah pekerja harian lokal yang dipekrjakan oleh perusahan jika di hitung pendapatan perkapita pertahun adalah sebagai berikut:

\begin{tabular}{|l|l|l|l|}
\hline \multicolumn{1}{|c|}{$\begin{array}{c}\text { Jumlah tenaga } \\
\text { kerja }\end{array}$} & \multicolumn{1}{|c|}{ Upah } & \multicolumn{1}{|c|}{ Bulan } & Tahun \\
\hline $\begin{array}{l}103 \text { tenaga kerja } \\
\text { tetap }\end{array}$ & Rp.2.201.913 & Rp.226.797.039x12 & Rp.2,7 milyar \\
\hline $\begin{array}{l}50 \text { tenaga kerja } \\
\text { harian }\end{array}$ & Rp.80.000 & $\begin{array}{l}\text { Rp.4.000.000x3 } \\
\text { kali panen x 7 } \\
\text { lokasi aqua village }\end{array}$ & Rp.84.000.000,. \\
\hline
\end{tabular}

Untuk penguasaan lahan LSO menggunakan hak khusus yaitu HGU atau kata lain mengusahakan tanah yang bukan miliknya sendiri atas tanah yang di kuasai langsung oleh Negara untuk perusahaan pertanian,perikanan atau peternakan untuk tanah yang luasnya $5 \mathrm{Ha}$, berikut daftra luas tanah perusahaan-perusahaan LSO :

Tabel 1.2

daftra luas tanah perusahaan-perusahaan LSO

\begin{tabular}{|c|l|c|}
\hline No & \multicolumn{1}{|c|}{ Nama Perusahaan } & Luas Lahan $\mathbf{M}^{\mathbf{2}}$ \\
\hline 1 & PT. Suminelis Berkat Bersama & 138,700 \\
\hline 2 & PT. Bukit Sedap Aquakultur & 53,669 \\
\hline 3 & PT. Sumbawa Tiga Berkat & 79,990 \\
\hline 4 & PT. Sumbawa Tanjung Vannamei & 113,818 \\
\hline
\end{tabular}




\begin{tabular}{|c|l|c|}
\hline 5 & PT. Caridea Jaya Lestari & 179,964 \\
\hline 6 & PT. Sumbawa Delapan Penjuru & $76.942 / 82.347$ \\
\hline 7 & PT. Caridea Sumbawa AV 10 & 117,271 \\
\hline 8 & PT. Caridea Sumbawa AV 11 & 81,632 \\
\hline 9 & PT. Sumbawa Duabelas Makmur Sejahtera & 56,587 \\
\hline
\end{tabular}

\subsection{Penerapan kewirausahaan sosial}

Ketimpangan pendapatan identik menjadi masalah yang sering di hadapi oleh suatu daerah. Ketimpangan pendapatan yang cenderung tinggi dan ekstrim jika tidak segera diatasi akan menimbulkan terjadinya gejolak sosial di masyarakat seperti tingkat kriminalitas yang semakin tinggi, kesenjangan yang semakin parah antara golongan kaya dan miskin, dan penanganan maupun perbaikan yang semakin sulit dengan ketimpangan yang cenderung ekstrim. Sehingga untuk meminimalisir dampak dari ketimpangan pendapatan harus mengetahui faktor apa saja mempengaruhi ketimpangan pendapatan, hadirnya perusahaan-perusahaan LSO adalah bagian dari jawaban phenomena sosial teresebut, dapat di lihat dari skema contribusi:

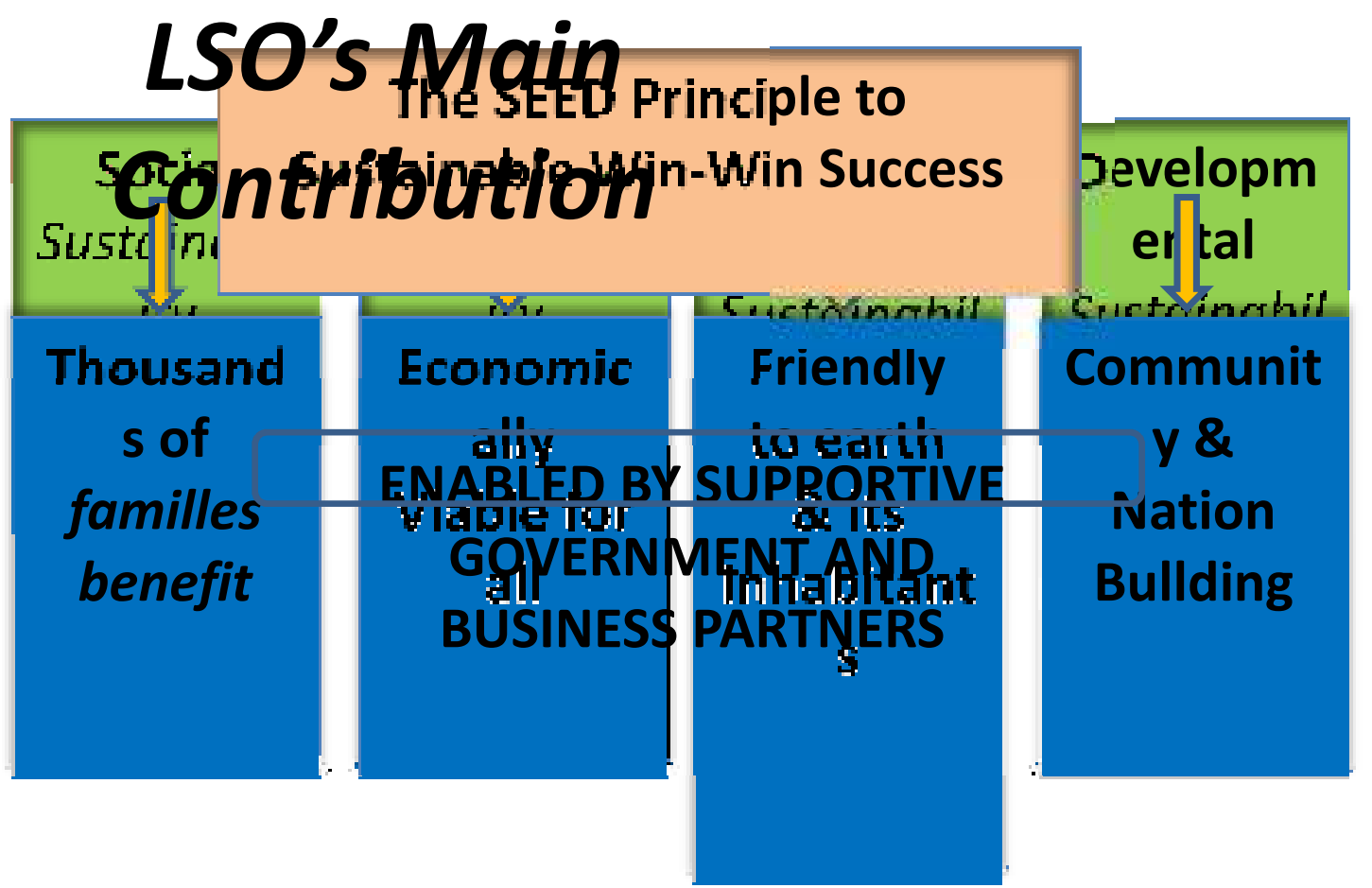

Sebagai perusahaan multi nasional dapat dilihat rekam jejak kontribusi sosial dalam tabel di bawah ini : 
Tabel 1.3

rekam jejak kontribusi sosial

Aqua Village Social Contribution-Livelihood Creation

\begin{tabular}{|c|c|c|}
\hline \multirow{2}{*}{$\begin{array}{l}\text { Direct hiring workers (with profit share } \\
\text { scheme and transfer of skill/Technology) }\end{array}$} & Direct & Indirect \\
\hline & 10 villagers & 30 family members \\
\hline \multicolumn{3}{|l|}{ Creating Entrepreneurs by outsourcing } \\
\hline Catering & 3 villagers & 9 family members \\
\hline Transport (Car) & 2 villagers & 6 family members \\
\hline Logistic (Truck) & 2 villagers & 6 family members \\
\hline Cleaning & 6 villagers & 18 family members \\
\hline Harvesting & 8 villagers & 24 family members \\
\hline Public Relation (Village \& Govt.) & 2 villagers & 6 family members \\
\hline Local Agri. Produce Supplies & 10 villagers & 30 family members \\
\hline Maintenance & 6 villagers & 18 family members \\
\hline Marketing & 2 villagers & 6 family members \\
\hline TOTAL & 51 villagers & 153 family members \\
\hline
\end{tabular}

Data di olah dari LSO

Konsep sosial kewirausahaan di lingkup perusahaan LSO dapat di lihat dalam tabel :

Tabel 1.4

Konsep keriwausahaan sosial

\begin{tabular}{|c|c|c|c|}
\hline Jenis usaha & Langsung & Tindak langsung & $\begin{array}{l}\text { Rata-rata } \\
\text { pendapatan }\end{array}$ \\
\hline Catering & $\begin{array}{l}\text { Perusahan memberikan } \\
\text { pengelolaan kepada } 3 \\
\text { koordinator di masing- } \\
\text { masing Aqua Village } \\
\text { yaitu } \\
\text {-makan sarapan } \\
\text {-makan siang } \\
\text {-Makan malam }\end{array}$ & $\begin{array}{l}\text { Kordinator membagi } \\
\text { kepada kepada ibu-ibu } \\
\text { untuk mempersiapkannya } \\
\text { Sarapan pagi } 3 \\
\text { orang,makan siang } 3 \text { orang } \\
\text { dan makan malam } 3 \text { orang } \\
\text { Jadi total wirausaha baru } \\
\text { untuk catering dari } 9 \mathrm{AV} \\
\text { sebanyak } 12 \text { orang perhari }\end{array}$ & $\begin{array}{l}\text { Jumlah } \\
\text { pendapatan } \\
\text { dari dari } 103 \\
\text { tenga kerja } \\
\text { adalah : } \\
\begin{array}{l}10.000 \times 3 \times 103=\mathrm{R} \\
\text { p. } 3.090 .0000\end{array}\end{array}$ \\
\hline $\begin{array}{l}\text { Sewa kendaraan } \\
\text {-car } \\
\text {-truk }\end{array}$ & $\begin{array}{l}\text { Perusahaan } \\
\text { memberikan peluang } \\
\text { kepada masyarakat } \\
\text { sekitar tambak untuk } \\
\text { menyediakan } \\
\text { kendaraan untuk di } \\
\text { sewakan } \\
\end{array}$ & $\begin{array}{l}\text { Perusahaan memberikan } \\
\text { peluang kepada masyarakat } \\
\text { kabupaten untuk } \\
\text { menyediakan kendaraan } \\
\text { untuk di sewakan }\end{array}$ & $\begin{array}{l}\text { Sewa car } \\
=\text { Rp.4.500.000/b } \\
\text { ulan } \\
\text { Sewa truk } \\
+ \text { Rp.8.000.000/b } \\
\text { ulan }\end{array}$ \\
\hline $\begin{array}{l}\text { Pengadaan bahan } \\
\text { baku batu dan } \\
\text { pasir }\end{array}$ & $\begin{array}{l}\text { Perusahaan } \\
\text { memberikan peluang } \\
\text { kepada masyarakat } \\
\text { sekitar tambak untuk } \\
\text { menyediakan material } \\
\text { pasir } \\
\end{array}$ & & $\begin{array}{l}\text { Harga } \\
\text { pasir=Rp.35.000 } \\
\text { /grobak }\end{array}$ \\
\hline $\begin{array}{l}\text { Pengadaan bahan } \\
\text { baku pagar }\end{array}$ & $\begin{array}{l}\text { Perusahaan } \\
\text { memberikan peluang } \\
\text { kepada masyarakat } \\
\text { sekitar tambak untuk } \\
\text { menyediakan material } \\
\text { pagar dari kayu yang } \\
\text { ada di wilayah desa }\end{array}$ & & $\begin{array}{l}\text { Harga satu } \\
\text { batang kayu } \\
\text { jawa Rp.5000 }\end{array}$ \\
\hline
\end{tabular}




\begin{tabular}{|l|l|l|l|}
\hline & setempat. & & \\
\hline Tenaga panen & $\begin{array}{l}\text { Perusahaan } \\
\text { memberikan peluang } \\
\text { kepada masyarakat } \\
\text { sekitar tambak untuk } \\
\text { terlibat pada saat panen }\end{array}$ & & Tenaga panen \\
& & \\
\hline
\end{tabular}

\section{KESIMPULAN DAN SARAN}

\subsection{Kesimpulan}

1. Potensi areal budidaya yang luas sepanjang garis pantai kabupaten Sumbawa merupakan peluang usaha/investasi yang potensial untuk menawarkan pada investor untuk berinvestasi.

2. Investasi di budidaya perikanan tambak udang tentu melibatkan masarakat luas dan menciptakan wirausawan baru

3. Termasuk komitas ekspor dan unggulan daerah dan Tingginaya permintaan pasar

4. Penyeraapan tenaga kerja yang besar/padat karya

5. Teknologi yang ramah lingkungan

\subsection{Saran}

1. Untuk menawarkan investasi tambak modern Keterbatasan inprastruktur pendukung harus sudah di antisipasi termasuk,Keterbatasan pasokan listrik,Keterbatasan tenaga terampil lokal;

2. Pemerintah di sarankan untuk membangun pelabuhan refresentatif, agar Ekspor/pengiriman antara dapat dilakukan secara langsung dari kabupaten Sumbawa.

3. Pemerintah di sarankan untuk membangun atau mencari investor pengolahan udang agar industrialisasi dapat terwujud . 


\section{DAFTAR PUSTAKA}

Burhan Bungin,Metodelogi penelitian kuantitatif,Kencana,Jakarta,2011,hlm.26.

Gunawan sumodiningrat, sistim ekonomi pancasila dalam perspektif,impact wahana cipta,Jakarta,1999,hlm.50.

Emil salim,membangun koperasi dan sistim ekonomi pancasila,UI press,Jakarta 1987,hlm.60.

Sunaryati hartono, beberapa masalah transnasional dalam PMA di Indonesia, Binacipta,Bandung,1972,hlm.8.

Peter van den bossche, The law and policy of the word trade organization,text cases and material,cambrige,2006.hlm.4.

Wibisono yususf, membedah konsep aplikasi CSR, 2007, the Jakarta

Nursahid ,word bisnis council for sutanable development,2006

Kotlend \& nanci, corporate stakeholder,pustaka utama graffiti,2005,Jakarta

Erterberg,qualitative methods ins sosial research ,mc graw hill,1984,newyork

Lain-Lain

Data Babpeda Kabupaten Sumbawa

Data Dinas Kelautan Dan Perikanan Kabupaten Sumbawa

Data Badan Pusat Statistik NTB

Data Dinas Penanaman Modal Dan Pelayanan Terpadusatu Pintu Kab.Sumbawa 